\title{
DIGITAL CULTURE, THE ANTHROPOLOGICAL DIMENSION AND THE EDUCATIONAL PROBLEM
}

\author{
Adriano Fabris ${ }^{1}$
}

\begin{abstract}
This essay explores the current state of communication by focussing in particular on two of its dimensions. They are: 1 . The increasingly massive and pervasive spreading of forms of digital communication, and 2. Some of the consequences such situation has on the general mentality and on the way the human being is understood. Of such consequences, it is above all the confusion between online and offline, that is between the two different environments that human beings can inhabit, and the confusion between the analogue and the digital, which are mainly investigated from an ethical point of view. A specific educational project is required to address such problems: a project that the ethics of ICT can inspire and give grounds for.
\end{abstract}

Keywords: ICT, Ethics, Communication Environments, Education

\section{CULTURA DIGITAL, A DIMENSÃO ANTROPOLÓGICA E O PROBLEMA EDUCACIONAL}

\begin{abstract}
Resumo: Este ensaio explora o estado atual da comunicação, concentrando-se em duas de suas dimensôes. São elas: 1. A disseminação cada vez mais massiva e difusa de formas de comunicação digital; e 2. Algumas das consequências que essa situação tem sobre a mentalidade geral e a maneira como o ser humano é compreendido. De tais consequências, é sobretudo a confusão entre online e offline, ou seja, entre os dois ambientes diferentes em que os seres humanos podem habitar, e a confusão entre o analógico e o digital, que são principalmente investigadas do ponto de vista ético. É necessário um projeto educacional específico para resolver esses problemas: um projeto que a ética das TIC possa inspirar e fundamentar.
\end{abstract}

Palavras-chave: TIC, Ética, Ambientes de Comunicação, Educação.

1 Professor of Moral Philosophy and Communication Ethics, University of Pisa, Italy. Email: adriano.fabris@unipi.it 


\section{Two dimensions in the current state of communication}

There are two dimensions that one should keep firmly in mind in the situation in which all of us, nowadays, communicate on a global scale. Firstly, we live in a situation that is more complex and wide-ranging than ever, even in terms of communicative experiences. Secondly, such situation, with which we interact, affects our behaviours every single day and dramatically changes them. First, ethical expertise and then a very specific educational effort are required to come to terms with this. Let's look at such dimensions.

The complexity of the state of communication we are living in today is partly the result of the recent developments of inter-human communication, and more generally of any form of communication that affects and involves human beings, even if produced by machines. On one side, the developments of communication result in a proliferation of tools and devices that make communication happen and which interweave and combine with each other into new pieces of equipment that are by now widespread. On the other side, communication itself, not least because of the proliferation of such equipment, has dramatically changed: from a relational system, it has turned into a living environment. That's why nowadays we can for instance carry on with and develop our relationships remotely, as it has been requested for example to avoid the spread of the coronavirus infection. But all this also involves the need to learn to re-set our relationship between online and offline.

The natural and artificial tools and devices we use when we communicate include, in the order in which they have appeared throughout history, the spoken word and the written word (e.g. in a book), sound carried by radio waves and images transmitted by television, electronically-shared data, and all that makes it possible to send and receive them. We all know how to use them, to some extent: we may be more or less skilled, depending on how good we are at interacting with some devices. However, having some degree of familiarity with each one of such communication systems is inevitable nowadays. Indeed, we are -so they saymultitaskers. But we must also be able to properly use such plethora of tools. We must be able to speak and write, to decode images and browse the Internet (Fabris, 2018).

The term "properly" however does not only stand for some technical skill. It involves an awareness of the meaning and the consequences of using such tools. It involves a specific background and a specific education. This is key to any communication skill. But I'll come back to this.

There's something else that is happening nowadays, though. We realise it precisely as we communicate. When I share a post, upload a picture on Facebook or inform my WhatsApp group of something, I am not just using my device. I rather inhabit, through my device, a number of contexts that add up to my daily life (which is my life outside of the Internet, the offline one) and which sometimes overlap and get mixed up with it. It is a further, specific dimension that is provided by technology. Actually, technology is not merely used by human beings, it does not merely depend on them to work, it almost independently provides specific 
contexts within which human beings can express and develop relations themselves. In a nutshell, technology is a new space to inhabit (Valera, Castilla, eds., 2019).

We have tried to live with all this. We are not only more or less experienced in how to use communication tools, we also know how to find our bearings in those additional, ever-new dimensions of communication, which communication technology is providing us with. Of course: the two dimensions - communication as a tool and communication as an environment - are in fact interwoven into each other. Indeed, they have always been, even though it is only with the recent technological advancements that the latter dimension has powerfully come to the fore. At any rate, our communication skills have necessarily had to expand. We certainly did not forget how to talk when we learnt to write; we did not stop reading and writing when we sat in front of a TV (even if we still had to divide our time between face-to-face relationships, books and TV, while all the time we spent in front of the screen was maybe making us unlearn the pleasure of reading or meeting people in the flesh). And no doubt we keep watching TV, reading and talking even we spend a lot of time on Social Networks.

Hence the fact that it is precisely in these dimensions that communication has an outstanding anthropological value, in other words it concerns human beings as such as well as in their multiple expressions. This is nothing new, since Aristotle has already defined man, in his essence, as an «animal that possesses logos», that can communicate. Nowadays, though, communication, as we saw, is taking a much more complex and far-ranging shape than it happened in Aristotle's time; it is used as a tool and is experienced as an environment. Actually, we are now increasingly surrounded by digital culture.

We have to get a better understanding of what this all means. We must reflect on how to come to terms with such situation. We must cope with it and teach others, especially the younger ones, to cope with it too. In this, ethics, communication ethics, can be helpful.

\section{Digital culture and the anthropological dimension}

But first we need to go through a few more steps. We have to explain some issues and even analyse the words we use. And then we must get a better understanding of the situation we are experiencing.

First and foremost, what does "digital" mean? What phenomenon does such word, which is by now a sort of label, stand for? And how does the phenomenon it stands for shape the mentality and culture of our time? And, more to the point, in what forms does it affect the multiple relationships we build with each other as human beings and between us and things?

The word "digital" defines the way in which, through some specific technology, sound and images, wherever they come from, are decomposed and combined together into a binary string of zeros and ones. In other words, every signal is brought back to such numerical sequence, encoded according to it, and 
converted into a packet of data. Information Technology is the science that deals with the processing and management of such data. It uses, for instance, algorithms, to do it: computational processes that solve a given problem in a very definite order and in a finite number of steps (Zellini, 2020).

Such digital standardisation is not, however, a natural or predictable process even if such approach is by now widespread in our culture. In fact, it is based on a number of assumptions and involves consequences. Assumptions and consequences were very lucidly expressed and predicted by Norbert Wiener in his Cybernetics: Or, Control and Communication in the Animal and the Machine (Wiener, 2013). Communication, in the multitude of meanings that such process has and in the different parties it can affect, turns into a mere transmission of information. Information is in turn brought back to a connection of data by digitising the signals and standardising them into a binary string of zeros and ones.

In other words, in digital information, data can be easily decomposed, manipulated, combined. Sending data is much easier than it used to be, and receiving them is much safer. Through digitisation, signals get faster and more powerful. This not only improves the effectiveness of communication networks, but above all it supports and fully integrates another process that has taken place in parallel, in the last decades of the $20^{\text {th }}$ century. I am speaking of the birth, first (i.e. in 1982), of the Internet Protocol Suite (TCP/IP), which made the transmission of data between computers through the telephone network possible, and, then (in 1989), the birth of the World Wide Web, a network of texts that gives users access to other texts infinitely, according - indeed - to the principle of hypertext (http: Hypertext Transfer Protocol).

As we know, all this marked the start of the Internet. However, the point here is not chronicling the three steps in the development of the Internet we have known so far: i.e. the step of the traditional Internet, consisting of interconnected websites, according to the principle of hypertext, which we can "surf"; the step of Social Networks, within which we are not mere users, but, most importantly, the producers of the contents we electronically share; and, lastly, the age of the so-called IoT (Internet of Things), within which machines that are by now interconnected can independently communicate with each other (Wilkins, 2019). In addition to all this, what matters most is getting a real insight into the consequences of the digital transformation of communication, the way in which, in such form, it becomes the prevalent culture and a living environment, its distinctive features and the ways its underlying dimensions affect our behaviours and our relationships. Actually, we are analogue beings, not digital ones: this means that we receive and reproduce by analogy all the signals that come from the world - with all the inaccuracy it involves and the need to be constantly engaged in an exegetic effort. So, we need to find a way to properly relate the two dimensions with each other.

What happens instead, what is plain to all, is different. The reductionist process that is at work in digital information, and that is part of its plan and makes it so widespread and successful, is somewhat normative. In other words, it becomes 
a standard for every form of relationship: even for the multiple and diverse ones that concern human beings. The absorption of the real into the virtual becomes something commendable. Adapting one's offline daily life to the standards of one's online experiences, thus creating the so-called "onlife" dimension (Floridi, 2014), is perceived to be a good thing.

Therein lies the problem. It is a problem that mainly concerns the ethical dimension: in the digital environment, communication boils down to a transmission of information, information in turn consists in sending a packet of data, and the latter are standardised into a binary string. There's no doubt that this has great advantages in terms of technological developments: advantages we all benefit from. But it also involves the risk of human beings losing their distinctive features and being levelled down to one dimension (Marcuse, 2002). In other words, such risk comes up when the digital, instead of being a specific way to process some form of communication, turns into the go-to standard for all interactions. In this way, it paves the way to a hegemonic culture, which claims it can explain the way human beings behave and wants to rule such behaviours (Han, 2013, 2015 and 2017).

When it happens, human communication too boils down to a mere transfer of data. And there's more than that: from such perspective, human beings operate just like cybernetic machines. Therefore, the distinction between human beings and machines, between the natural and the artificial, between men and robots, seems to vanish. Then, if it is true that objects can be infinitely reproduced through digitisation, with the original becoming indistinguishable from the copy and without having to invest too much money to produce or reproduce something, the same can happen to human beings. Once again, everything seems to be replicable: from behaviours, which have now been standardised, to body parts, and even human beings (Cavalier, ed., 2005).

However, if we look deeper into it, what stands out in digital culture and what might swamp the specificity of the human being as well is the general atmosphere of indifference. "Indifference" means the disappearance of every difference that first and foremost makes everything the same, similar, and makes us lose interest in someone or something. Interest is actually based on our perception of the peculiarities, of the specific differences, that belong to any being. If such differences are effaced -if for instance humans and machines work alike, if, because of such similar way of working, human beings are standardised, or if their very nature is turned into an artificial product- then, in the end, nothing matters about all that: human beings, nature, machines.

So here is the common mentality, the widespread culture that nowadays might gain the upper hand and leave a deeper and deeper mark on the world we live in. We often live in it by adapting to such culture, by accepting it unquestioningly. And then we don't make a proper distinction between our everyday experiences and what we only do online. In other words, we behave as digital beings, though we are analogue beings. We accept a sort of "voluntary servitude" to mechanisms that we may have built ourselves but that have now been imposed on us (de la Boëtie, 
2016). We give up our freedom of choice, within the limits and in the areas where we can assert it, and conform to the procedures we are shown.

In all these circumstances, we need to get back all the options that belong to us and that are our distinctive traits as human beings. We need to take inspiration from such opportunities, especially in the area of communication, as communication is a quintessentially human feature. Then, we need to extend such advantage to all the relations we may ever be involved in. We need to educate ourselves and others to live in these different worlds, while keeping them separate and taking advantage of the opportunities each one provides.

This means definitely altering the course of what we are used to doing. Ethics can help us do it. Or to be precise: communication ethics can.

\section{Human beings, the educational problem and communication ethics}

Human beings are analogue beings. Human beings communicate in many different ways. As opposed to what happens in some unilateral outcomes, which are the product of invariably similar procedures that make everything undistinguishable, human beings open up opportunities. They can open up opportunities because they live in time: that is, they live in the present, they know they are rooted in the past, and they lean out to the future. They live in time -and live time- because they live in the world, and of the world they experience the many relationships they are constantly involved in. Then, such world is felt to be a hotbed of opportunities, always open to more opportunities.

As a matter of fact, we accomplish our plans firstly by getting out of ourselves, out of the enclosed places we take shelter in. In enclosed places, we can't last. We have realised this in these last few weeks too, when the pandemic forced us to stay at home. In these last few weeks, most of our relationships have been long-distance relationships. ICT has given us the opportunity to keep such relationships afloat. But soon enough we realised that such relationships are not the same as those that are mediated by our bodies and that take place closely, in face-to-face interactions.

Actually in our lives we inhabit the relationships and the contexts in which they can grow, we receive an education that enables us to inhabit such contexts, and we teach other people to navigate such contexts, by enjoying all that ever-new relationships can give us. But to do this, we need to fit in with the environment that is quintessentially human. And we need to learn to properly inhabit it.

Such environment is the communication environment. To properly inhabit it, to make the right choices, we need to make an ethical reflection. We need to know what criteria and principles can guide us through such choices. Communication ethics is the discipline in charge of establishing such principles and inspiring people to let themselves be guided by them. It deals with all forms of communication: spoken, written, audio visual, as well as digital communication (Fabris, 2014).

In this day and age, it is important for us to come to terms with that digital culture that is, in many respects, the prevailing one and to address the risky elements 
that it involves, when it is unquestioningly accepted. Above all, it is important for us to teach others to address such problems. The first thing we should say about this is that, in relationships among human beings, communication is never a mere transfer of data. Of course, when we communicate -whatever medium we use- we share with others the specific contents that we somehow "send" them. But, moreover, it is just by communicating that we express our readiness to interact or not and that we create those spaces within which communication becomes possible and can always be further expanded. We certainly use tools to do it, but the intention and the consequences of our using them go far beyond the mere fulfilment of a procedure. Communicating -as also proven by the etymology of the verb (to communicate)means opening a common space, and means - even deeper down-an opportunity to share what one has and what one is.

That's why, as it is more and more often happening today, communication can turn into an environment. It is not, however, just an artificial environment, which has been created by technology and which only partly depends on us to operate. It is rather a living environment, within which, just through our communication skills and the tools it expresses itself with, we build and strengthen relationships, we open up opportunities for ourselves and for others, we accomplish ourselves in all that we are. That's why, again, communication is an ethical issue: because, when we perform it, we are constantly brought back to the choices that enable us to behave properly or improperly, in such environment.

It is not just procedures that apply here. Just sticking to a rule is not enough, if we want to communicate well. Behaving "properly" does not mean doing it "effectively and efficiently". It means instead working in a way that can support and keep up with the profitable relationships that make a community possible. To do this, one needs to understand the context and maybe adapt to it. It takes resourcefulness: which cannot be programmed, which cannot be broken down into a digital sequence.

We must teach all of this. We must teach others to think of such situation. We must teach others to navigate it properly. This can be achieved when we are taught to embrace different forms and modes of communication, to apply them according to our purposes, to understand that any communication involves choices, which must be guided by shared principles. All this is the area of study of an education to communication and to its tools (Spector, Merrill, Elen, Bishop, 2014). However, all this demands that the potential criteria of our communicative action are clearly understood, first.

As I said, it is communication ethics that can help us do that. More than of an insider discipline, though, we should speak of an opportunity for reflection that concerns everybody. And that moves along three lines of investigation. Firstly, communication ethics provides a critical background that prevents conformism, the blind adherence to a shared mentality. And on that basis the key question in communication ethics is: what underlies the concepts that steer our communicative action? Then, communication ethics can bring into focus the specific human quality 
that is expressed in communication. From this perspective, the distinction between communication in humans and communication in machines, as well as between the ways in which such different forms of communication can properly connect with each other, clearly comes to the fore. Lastly, communication ethics helps us get our bearings, based on specific paradigms, in the choices that we have to make whenever we communicate, whether we do it in our everyday life or whether it is our job (as it happens in deontology). Therefore, it not only helps understand what proper communication means, it also reminds us of the responsibility that is unique to any agent and of the trust that is demanded of any communicative interaction (Fabris, ed., 2020).

In conclusion, then, it is just by taking inspiration from this ethical background that we can come to terms with the digital culture that we are immersed in nowadays. We can take its opportunities and its risks. We can understand them and we can teach others how to cope with them. We can understand that all this is about properly using those opportunities that are our distinctive features as human beings. In other words, it is by taking inspiration from all this that we can understand what we are and what we can be. Or better: we can be ourselves, and be our best selves, just when we communicate.

\section{References}

DE LA BOËTIE, E. Discourse of Voluntary Servitude, New York: Adagio Press. 2016.

HAN, B.-Ch. The Burnout Society, Stanford: Stanford U.P. 2013.

HAN, B.-Ch. The Transparency Society, Stanford: Stanford U.P. 2015

HAN, B.-Ch. Psychopolitics: Neoliberalism and New Technologies of Power, Stanford: Stanford U.P. 2017.

CAVALIER, R. J., (ed.). Impact of Internet on Our Moral Lives, Albany: State University of New York Press. 2005.

FABRIS, A. Etica della comunicazione, Carocci, Roma. 2014.

FABRIS, A. Ethics of Information and Communication Technology, Berlin-New York: Springer. 2018.

FABRIS, A., (ed.). Trust: A Philosophical Approach, Berlin-New York: Springer. 2020.

FLORIDI, L. The Fourth Revolution: How the Infosphere is Reshaping Human Reality, Oxford-New York, Oxford U.P. 2014.

MARCUSE, H. One-Dimensional Man. Studies in the Ideology of Advanced Industrial Society, London, New York: Routledge. 2002.

SPECTOR J.M, MERRILL M.D., ELEN J., BISHOP M.J. Handbook of Research on Educational Communications and Technology, Berlin-New York: Springer. 2014. 
VALERA, L., CASTILLA, J.C., (eds.). Global Changes. Ethics, politics and Environment in the Contemporary Technological World, Berlin-New York: Springer.

WIENER, N. Cybernetics: Or, Control and Communication in the Animal and the Machine, Eastford: Martino Fine Books. 2013.

WILKINS, N. Internet of Things, Oxford: Bravex Publications. 2019.

ZELLINI, P. The Mathematics of the Gods and the Algorithms of Men: A Cultural History, Cambridge: Pegasus Books. 2020. 